\title{
ORTHOGONALITY FOR A CLASS OF GENERALISED JACOBI POLYNOMIAL $P_{v}^{\alpha, \beta}(x)$
}

\section{N. J. Ford, H. MOAYYed AND M. M. RodRigues}

Abstract. This work considers g-Jacobi polynomials, a fractional generalisation of the classical Jacobi polynomials. We discuss the polynomials and compare some of their properties to the classical case. The main result of the paper is to show that one can derive an orthogonality property for a sub-class of g-Jacobi polynomials $P_{v}^{(\alpha, \beta)}$. The paper concludes with an application in modelling of ophthalmic surfaces.

Mathematics subject classification (2010): 33F05, 33C90, $12 \mathrm{E} 10$.

Keywords and phrases: Jacobi polynomials, approximation, optic modelling.

\section{REFERENCES}

[1] M. Abramowitz And I. A. Stegun (eds.), Handbook of Mathematical Functions with Formulas, Graphs, and Mathematical Tables, National Bureau of Standards, Applied Mathematics Series 55, 9th printing, Washington, 1970.

[2] W. Burnside, A rapidly convergent series for $\log N$ !, Messenger Math. 46, 1 (1917), 157-159.

[3] M. Abramowitz, I. A. Stegun, Handbook of Mathematical Functions with Formulas, Graphs, and Mathematical Tables, Dover Publications, New York, 1974.

[4] S. D. BAJPAI, A new orthogonality property for the Jacobi polynomials and its applications, Nat. Acad. Sci. Lett. 15 (1992), 221-226.

[5] F. Bowman, Introduction to Bessel Functions, Dover Publications Inc., New York, 1958.

[6] M. ChEn AND H. M. SRIVASTAVA, Orthogonality relations and generating functions for Jacobi polynomials and related hypergeometric functions, Applied Mathematics and Computation 68 (2-3) (1995), 153-188.

[7] T. S. Chinara, An Introduction to Orthogonal Polynomials, Gordon and Breach Science Publishers, New York-London-Paris, 1978.

[8] G. Csordas, M. Charalambides And F. WalefFe, A new property of a class of Jacobi polynomials, Proc. Amer. Math. Soc., 133 (12) (2005), 3551-3560.

[9] C. Ferreira, J. L. Lpez, R. NAvarro And E. Prez Sinus A, Orthogonal basis with a conicoid first mode for shape specification of optical surfaces, Opt. Express 24 (5) (2016), 5448-5462.

[10] E. Gogovcheva AND L. BoyAdJIEv, Fractional extensions of Jacobi polynomilas and Gauss hypergeometric function, Fract. Calc. Appl. Anal. 8 (4) (2005), 431-438.

[11] B. Guo, J. SHEn AND L. WANG, Generalized Jacobi polynomials/functions and their applications, Appl. Numer. Math. 59 (2009), 1011-1028.

[12] S. D. Klyce, M. D. Karon And M. K. Smolek, Advantages and disadvantages of the Zernike expansion for representing wave aberration of the normal and aberrated eye, J. Refract Surg. 20 (5) (2004), 537-541.

[13] J. KoeKOEK AND R. KoEKoEK, Differential equations for generalized Jacobi polynomials, J. Comput. Appl. Math. 126 (1-2) (2000), 1-31.

[14] A. J. Lambert, E. M. Daly And C. J. Dainty, Improved fixation quality provided by a Bessel beacon in an adaptive optics system, Ophthalmic Physiol. Opt. 33 (4) (2013), 403-411.

[15] S. P. Mirevski, L. Boyadjiev And R. Scherer, On the Riemann-Liouville fractional calculus, g-Jacobi functions and F-Gauss functions, Appl. Math. Comput. 187 (1) (2007) 315-325. 
[16] N. I. NAGNiBIDA, Completeness in analytic spaces of subsequences of Laguerre and Jacobi polynomials, Mathematical notes of the Academy of Sciences of the USSR 7 (3) (1970), 182-186.

[17] I. Podlubny, Fractional differential equations: An introduction to fractional derivatives, fractional differential equations, to methods of their solution and some of their applications, Academic Press, San Diego, California, 1999.

[18] A. P. Prudnikov, Yu. A. BrychKov And O. I Marichev, Integrals and series: More special functions, Gordon and Breach Science Publishers, New York, 1990.

[19] A. P. Prudnikov, Yu. A. Brychkov And O. I Marichev, Integrals and Series: Elementary functions, Gordon and Breach Publisher, New York, 1986.

[20] V. Romanovski, Sur quelques classes de polynomes orthonaux, C. R. Acad. Sci. Paris 188 (1929), $1023-1025$.

[21] S. G. Samko, A. A. Kilbas And O. I. Marichev, Fractional integrals and derivatives: theory and appllications, Gordon and Breach, New York, 1993.

[22] T. SAKAi AND L. G. RedeKopP, An application of one-sided Jacobi polynomials for spectral modeling of vector fields in polar coordinates, J. Comput. Phys. 228 (18) (2009), 7069-7085.

[23] G. Szegö, Orthogonal Polynomials, American Mathematical Society, Providence, Rhode Island, 1958.

[24] M. TAKenchi, Modern spherical functions, American Mathematical Society, Providence, Rhode Island, 1994.

[25] Methods for reporting optical aberrations of the eye, American National Standard for ophthalmics, ANSIZ80.28-2010, Washington, DC: American National Standards Institute, 2010. 